\title{
Roteiro Para Avaliação E Seleção De Atividades Didáticas De Língua Inglesa Na Compreensão Escrita
}

Checklist for Evaluation and Selection of English Educational Activities in Reading Comprehension

Maria Catarina Paiva Repolês, doutoranda em Estudos de Linguagens, CEFET/MG, catarina.repoles@ifsudestemg.edu.br;

\section{Resumo}

A EJA objetiva reinserir no sistema escolar jovens/adultos com trajetórias escolares truncadas. A esta política educacional de inclusão social subjazem a formação do professor e materiais pedagógicos próprios para a modalidade. Uma pesquisa resultou em um roteiro para orientar professores na avaliação/seleção de materiais didáticos para o ensino-aprendizagem de Inglês de forma prática e factível.

Palavras Chave: roteiro, Língua Inglesa, atividades didáticas.

\begin{abstract}
Young and Adult Education aims at reinserting in the school system those with interrupted school careers. This educational policy of social inclusion involves the formation of teachers and adequate teaching/learning materials for this modality. A research resulted in a checklist to guide teachers in the evaluation/selection of English teaching materials in a practical and feasible way.
\end{abstract}

Keywords: checklist, English language, educational activities. 


\section{Introdução}

O objetivo deste artigo é apresentar um roteiro como sugestão de avaliação e seleção de atividades didáticas de Língua Inglesa - LI para os cursos do PROEJA (Programa Nacional de Integração da Educação Profissional com a Educação Básica na Modalidade de Educação de Jovens e Adultos), com foco na compreensão escrita. Esse roteiro resultou de uma pesquisa sobre o material didático disponível para a modalidade EJA, à época, e entrevistas com professores de quatro cidades da Zona da Mata, cujas escolas ofereciam o PROEJA. A análise do material obtido na pesquisa foi feita pelo método de análise de conteúdo (BARDIN, 1977) servindo de base para o roteiro. Foram, também, considerados os critérios de avaliação para o componente curricular de língua estrangeira moderna, propostos no Programa Nacional do Livro Didático, o PNLD EJA 2011 (BRASIL, 2009) e alguns conceitos teóricos que serão brevemente considerados aqui.

Embora a pesquisa tenha sido feita no âmbito do PROEJA e visando o material didático de LI, acreditamos que o roteiro a ser apresentado seja um recurso que enfatiza a individualidade, respeitando as diferenças, podendo, assim, ser usado por outras disciplinas na Educação de Jovens e Adultos.

A seguir uma breve apresentação do PROEJA, alguns dos conceitos teóricos que subjazem o roteiro, e alguns fatores que intervêm no processo de ensinoaprendizagem de LI para esse público que busca, principalmente, a inclusão social.

\section{PROEJA}

O PROEJA, foi implantado nas instituições públicas por meio do Decreto no 5.840 de 13 de julho de 2006 com o objetivo de resgatar e reinserir no sistema escolar brasileiro os jovens e adultos com trajetórias escolares truncadas.

Apoiado na convergência de três campos da educação que são a formação para o mundo do trabalho (EPT), para o exercício da cidadania (Educação Básica) e as especificidades da educação de jovens e adultos (EJA), o PROEJA é, pois, como o próprio nome diz um programa para proporcionar formação profissional com escolarização (ensino médio e/ou fundamental) para jovens e adultos, buscando uma formação humana mais geral. Segundo consta no Documento Base do PROEJA (BRASIL, 2007, p.35), "A formação assim pensada contribui para a integração social do educando, o que compreende o mundo do trabalho sem resumir-se a ele, assim como compreende a continuidade de estudos". Nesse contexto, a Rede Federal de Educação Profissional e Tecnológica teve papel de referência.

Entendemos, porém, que a eficácia dessa política educacional de inclusão social subjaz a necessária formação do professor e de materiais pedagógicos próprios para o público da modalidade. 
Abordagem Teórica

Para referenciar os sujeitos alunos e a relevância da educação na modalidade EJA nos apoiamos no Documento Base do PROEJA e PROEJA/FIC (BRASIL, 2007 e 2009). Os Parâmetros Curriculares Nacionais: ensino médio - PCNEM (BRASIL, 1999) e autores que discutem o ensino-aprendizagem de idiomas nas escolas públicas são nosso alicerce na discussão sobre ensino de inglês, formação de professores e alunos, letramentos, gêneros e adequação do material didático (BATISTA, 1999; FREIRE, 2009; LEFFA, 2001, 2007; SOARES, 2006 e outros).

Muitos são os aspectos conflitantes dentro da modalidade EJA, como o aumento substancial de jovens buscando recuperar a defasagem série-idade, a falta de investimentos, ou professores que desconhecem o perfil dessa modalidade de ensino.

O Documento Base do PROEJA (BRASIL, 2007) retoma as características desse contingente, jovens e adultos não escolarizados, a descontinuidade das políticas públicas, e as restrições e equívocos que vêm perpetuando uma educação precária para esse público.

As diretrizes teórico-metodológicas preconizadas pelo Documento Base fundamentam a nossa proposta de trabalho sobre avaliação e seleção de materiais didáticos para as aulas de LI, considerando as especificidades dos alunos da EJA, a importância do multiletramento, do conhecimento de outra cultura, da inserção das TDIC, outros fatores constituintes do processo de ensino/aprendizagem e da inclusão social.

Em nossa sociedade cada vez mais grafocêntrica é imprescindível adquirir as competências para envolver-se com as práticas sociais de leitura e escrita. A pessoa letrada passa a ter outra condição social e cultural. Soares (2006) apresenta, na dimensão social, tanto o letramento funcional, tido como uma interpretação fraca e liberal do conceito, quanto uma interpretação "revolucionária" (ênfase no original) "gerada por processos sociais mais amplos, e responsáveis por reforçar ou questionar valores, tradições e formas de distribuição de poder presentes nos contextos sociais." (ibid., p.75).

O conceito de letramento varia segundo as necessidades e situações históricas. Assim, Soares (2006) e outros autores defendem a pluralização do termo para letramentos. Estudar os tipos de letramento é, para Xavier (2002, p. 6), "uma parte do estudo dos gêneros de texto, para saber como eles são produzidos, utilizados e adaptados a cada situação vivida pelo indivíduo pertencente a uma dada comunidade". Portanto, a escolha de gêneros que possam estabelecer relações com os conhecimentos de outras áreas, ou temáticas sociais urgentes, presentes na mídia ou necessários à profissão do aluno, por si só já lhe oferecerão um trabalho de interação com o meio.

Os gêneros discursivos emergentes advindos de usos dos novos suportes tecnológicos também precisam encontrar espaço nas salas de aula, como meios de 
evitar um distanciamento entre a educação escolar e o novo modelo de sociedade informacional. Marcuschi (2005, p.20) esclarece que é "a intensidade dos usos dessas tecnologias e suas interferências nas atividades comunicativas diárias" que propiciam o surgimento dos novos gêneros. Parte daí a importância das TDIC no ambiente escolar e, consequentemente, do letramento digital.

Esses conceitos apresentados devem ser constituintes do material didático. Batista (1999, p.534) menciona a "construção do fenômeno de letramento no país" por meio do material didático e o papel de formação que este deve ter, seja ele destinado à escola ou apenas utilizado por ela. Isso requer construir as bases escolares amparadas na reflexão. A escola precisa ser reflexiva, muito mais do que informativa. ii

Freire (2009) também nos adverte para a importância da formação integral do ser humano como meio de enfraquecer a verticalidade das intervenções pedagógicas. Para o autor:

[transformar] a experiência educativa em puro treinamento técnico é amesquinhar o que há de fundamentalmente humano no exercício educativo: o seu caráter formador. Se se respeita a natureza do ser humano, o ensino dos conteúdos não pode dar-se alheio à formação moral do educando. (FREIRE, 2009, p. 33)

Quanto à formação dos professores Leffa (2007) discute o despreparo destes em Língua Estrangeira como um terceiro fator que contribui para a autoexclusão do alunoiii. Com a proliferação dos cursos de Letras o ensino superior passa a contribuir pouco para a preparação do futuro professor. Para Leffa, isso se torna ainda mais preocupante se o nível de proficiência do aluno que entra na universidade já é baixo.

Opinião similar é expressa por Oliveira (2009, p. 29): "Intuitivamente, considero seguro afirmar que a grande maioria dos professores de línguas estrangeiras nas escolas públicas no Brasil falam muito pouco ou não falam a língua estrangeira que lecionam."

O autor também menciona o fato de que a globalização tem levantado debates envolvendo questões sobre diferenças culturais, alteridade e multiculturalismo, que contribuem com a construção da cidadania. Segundo o autor a contribuição da língua estrangeira assim é dada:

Nesse sentido, ao estudar uma língua estrangeira, o estudante entra em contato com outra cultura, o que contribui para que ele conheça aspectos culturais diferentes daqueles presentes na sua comunidade. Isso pode levar o estudante a um processo de reflexão acerca do outro e de si próprio. Afinal o mundo social do estudante brasileiro é influenciado por aspectos econômicos, políticos e culturais das sociedades de outros países. (OLIVEIRA, 2009, p.27) 
À construção da cidadania subjaz o aumento da autopercepção do aluno contribuindo com o desenvolvimento da consciência cultural deste. Para Oliveira, esta é uma das funções do ensino da língua estrangeira em nossas escolas.

Outros conceitos considerados na pesquisa como a Andragogia, motivação, English for Specific Purposes não serão discutidos aqui.

\section{Fatores Intervenientes no Processo de Ensino/Aprendizagem}

Entre os fatores que interferem nos processos de ensino/aprendizagem de LI nas escolas públicas procuramos ressaltar aqui alguns que, a partir deste estudo, nos direcionaram para a elaboração do roteiro em questão.

Os professores, embora com formação dupla, relataram maior experiência de trabalho com aulas de Português e especializações na área de Português e Literatura. A rotatividade dos professores da EJA é grande, a experiência inicial e ausente nos currículos de formação na maioria das Instituições de Ensino Superior. Entendemos, então, que apesar dos avanços, esta modalidade mantém uma posição secundária na política educacional, perpetuando sua história de voluntarismo, amadorismo e improvisação, sempre à sombra do ensino dito regular.

Sobre a seleção do material didático de LI para as séries seguintes à alfabetização percebeu-se a unanimidade dos professores quanto ao seu desconhecimento. O MEC, buscando fomentar a produção de obras didáticas para a EJA, realizou, pela primeira vez, uma chamada pública para processo de avaliação sistemática de coleções didáticas destinadas à EJA com o PNLD EJA 2011 para as séries do ensino fundamental.

A dificuldade com atividades próprias para o PROEJA no Ensino Médio ainda são maiores se considerarmos a variedade de cursos técnicos oferecidos e a proficiência do professor de línguas para aliar o ensino da LI ao perfil do curso técnico. Essa escassez de materiais didáticos específicos tem levado muitos docentes a usarem os materiais de ensino regular, não raro sem as necessárias adequações, constituindo-se tão somente por uma redução de conteúdos.

Assim, quanto à seleção e preparação do material didático pelos professores percebemos, através de seus depoimentos, que o trabalho pedagógico baseava-se muito mais na intuição do professor do que na aplicação intencional e consciente de abordagens e metodologias específicas de ensino. Em razão do pouco conhecimento de trabalho com a língua estrangeira na modalidade, a maioria dos professores acabou por reforçar a ideia de atraso e dificuldade de aprendizagem que é o conhecido estereótipo do público da EJA. Todos os entrevistados enfatizaram a seleção de atividades muito básicas.

A inadequação do material didático para o público adulto recai muito nas atividades infantilizadas, retiradas na maioria de livros destinados ao ensino regular, apostilas de gramática, ou textos artificiais que pouco contribuem para o caráter 
educativo da disciplina, a construção de conhecimentos e o multiletramento necessários à formação integral do aluno.

Assim a ausência de atividades contemplando o estudo dos gêneros textuais fica evidente, embora sejam eles reconhecidamente facilitadores da aprendizagem de LI. Para a área de Linguagens, Códigos e suas Tecnologias, "O estudo dos gêneros discursivos e dos modos como se articulam proporciona uma visão ampla das possibilidades de usos da linguagem [...]." (PCNEM, 1999, p.18).

Já o letramento digital permanece incipiente, se considerarmos a sua efetivação no âmbito escolar. A inserção das TDIC no ambiente escolar tem ficado restrita aos escritórios, aos trabalhos burocráticos, à convivência e relacionamento de professores e funcionários, deixando de exercer um papel inovador de inclusão para os alunos. Percebemos, no entanto, que embora não fazendo uso das TDIC efetivamente em sala de aula, com os alunos, os professores recorrem a essas tecnologias com frequência na busca por atividades didáticas.

Considerando os fatores que intervêm nas práticas pedagógicas e, ciente de que nem todos poderiam ser solucionados através de um roteiro, não houve a pretensão de sugerir uma solução para o ensino-aprendizagem de LI no PROEJA. No entanto, devido à referência nos programas de avaliação e análise de livros didáticos sobre a precariedade de materiais educacionais para a modalidade, em especial para os anos finais da educação fundamental e para o ensino médio, um roteiro pode ser um diferencial importante, principalmente se considerarmos a abrangência da área técnica oferecida.

Ainda, como visto pelas entrevistas, os professores são, na sua maioria, itinerantes ou têm as aulas de LI como complemento de um cargo de outra matéria. Portanto, pontuar alguns conceitos a serem considerados na seleção e preparação das atividades poderia ser potencialmente relevante para eles.

O objetivo foi criar uma lista simples, que não exigirá do professor uma leitura extensa, cansativa ou que Ihe tome muito tempo inviabilizando o seu uso prático. Consideramos aqui a jornada dupla de trabalho da maioria desses profissionais.

O que deverá nortear o trabalho do professor nesse roteiro, em particular, refere-se ao conhecimento do Programa PROEJA e do perfil do aluno. São itens de potencial importância, haja vista a pouca preparação sobre estes com que os professores iniciam seus trabalhos com a modalidade.

\section{Sugestão de roteiro para avaliação e seleção de atividades didáticas de LI para o PROEJA: compreensão escrita}

1. O texto selecionado se adéqua à faixa etária correspondente aos sujeitos que buscam o PROEJA?

1.1. O assunto do texto é de interesse do público jovem-adulto desta determinada turma?

1.2. O assunto do texto trata de temas atuais? 


\section{V SILID IV SIMAR \\ PUC-Rio - Dias 28, 29 e 30 de julho de 201}

1.3. O assunto do texto respeita as diferenças, não reforçando estereótipos ou preconceitos?

1.4. A linguagem do texto é adequada ao nível de proficiência do aluno?

2. O texto selecionado contempla um gênero diferente daqueles usados em aulas anteriores, e direciona para a ampliação dos letramentos do aluno?

2.1. O trabalho com o texto vai abordar o uso social do gênero em destaque?

2.2. O trabalho com o texto vai abordar o papel do suporte, a adequação linguística, a escolha do tipo textual, a inserção de gravuras e ícones e outras relevâncias constitutivas do gênero?

2.3. O trabalho com o texto vai abordar os diferentes tipos de conhecimento: de mundo, textual e sistêmico?

3. O texto selecionado tem caráter formativo?

3.1. O estudo do texto leva o aluno a refletir sobre o seu envolvimento nas questões sociais?

3.2. O texto poderá ser usado para mediar a reflexão do aluno sobre seu papel na família, trabalho, comunidade a que pertence?

3.3. O texto levará o aluno a discutir a cultura dos diferentes países onde os povos têm a LI como primeira ou segunda língua?

3.4. O texto levará o aluno a refletir sobre a função social da LI?

3.5. A atividade proposta estimula o desenvolvimento do senso crítico do aluno?

3.6. As atividades com o texto exploram a intertextualidade, buscando outros textos ou informações além dos limites da aula?

4. O texto selecionado promove a interação do aluno com o meio, os colegas/professores, com o próprio texto?

4.1. As atividades privilegiam o trabalho em pares ou grupos?

4.2. O aluno poderá interagir com os espaços culturais ou de lazer da cidade ou proximidades?

4.3. As atividades motivam o aluno à interação com o assunto além do horário restrito das aulas?

4.4. As atividades poderão ser desenvolvidas de modo interdisciplinar?

5. Há interface entre o texto escolhido e as TDIC?

5.1. O texto ou as atividades propostas poderão ser desenvolvidos no meio digital?

5.2. Poderei fornecer um link adicional para que o aluno amplie o tema estudado, assista a um vídeo, participe de uma votação em rede, etc., através do acesso à internet?

5.3. Poderei sugerir uma tarefa a ser realizada com uma câmera de celular, como um folheto sobre um produto, ou um grupo musical com fotos dos alunos? 


\section{V SILID IV SIMAR

6. As atividades propostas são claras, precisas e variadas?

6.1. Os objetivos da atividade são claramente informados?

6.2. As atividades são variadas para atender aos diferentes estilos de aprendizagem dos alunos?

6.3. As atividades estão contextualizadas?

6.4. O processo de compreensão do texto acionará as estratégias de skimming ${ }^{\mathrm{iv}}$ e scanning ${ }^{\mathrm{v}}$ ?

6.5. Há margem de tempo na atividade para que o feedback seja oferecido ao aluno?

7. O texto contempla a área técnica desenvolvida no curso nos conteúdos profissionalizantes?

7.1 O vocabulário apresentado no texto está relacionado à aprendizagem profissional do aluno?

7.2 O gênero textual abordado é parte constitutiva da área profissionalizante, podendo contribuir com o crescimento do aluno no mundo do trabalho?

8. As cópias ou apresentação do material selecionado são legíveis e de qualidade?

8.1. As gravuras são nítidas?

8.2. O tamanho da letra é adequado para uma leitura noturna, ou por pessoas de maior idade?

8.3. O texto, ilustrações e exercícios são isentos de erros e inadequações?

8.4. Os devidos créditos e fontes dos textos são citados e trabalhados como meio de pré-leitura?

\section{Considerações Finais}

Subjazem à elaboração do roteiro os conceitos discutidos nos documentos oficiais e nas teorias que embasaram a pesquisa. Estes foram, direta ou indiretamente, incluídos nas entrevistas com os professores participantes. O roteiro foi dividido em 8 principais questionamentos.

No item 1, a seleção das atividades didáticas deve considerar principalmente o perfil do aluno segundo apresentado nos Documentos Base do PROEJA e do PROEJA/FIC, e que perpassa toda a literatura relacionada à EJA.

No item 2 a avaliação e seleção das atividades devem considerar a compreensão e interpretação de informações veiculadas em textos de natureza diversificada, considerando seu papel sociocomunicativo, contextualizando tópicos gramaticais e vinculando seu uso a situações de interação social, segundo a teoria dos gêneros.

No item 3 deve-se considerar o caráter educativo da disciplina, os espaços de construção de conhecimento, a globalização. "Abandona-se a perspectiva estreita de 
formação para o mercado de trabalho, para assumir a formação integral dos sujeitos, como forma de compreender e se compreender no mundo." (BRASIL, 2007, p.43)

No item 4 a seleção das atividades didáticas deve considerar o diálogo, a interação e a interdisciplinaridade.

No item 5 deve-se ponderar sobre a proliferação do uso das tecnologias digitais, o impacto e a função social das tecnologias mais recentes, os gêneros digitais, seja para a fruição, trabalho ou necessidade pessoal. Segundo os PCNEM (1999) é necessário incorporar necessidades da realidade ao currículo escolar para que o aluno possa acessar conhecimentos que serão exigidos no mundo do trabalho.

No item 6 é necessário atentar para a clareza e compreensão dos objetivos de cada atividade, dos diferentes estilos de aprendizagem, das estratégias de leitura e o feedback.

No item 7 a avaliação e seleção das atividades deverão considerar os aspectos relacionados à área técnica e ir além de situações passivas, de realização de tarefas mecânicas.

No item 8 é necessário considerar a legibilidade, o layout e referências do material escolhido.

Os itens listados poderão levar os profissionais de ensino a refletirem sobre sua prática, bem como acessar insights sobre a melhor escolha de atividades. Independente de serem as aulas preparadas paulatinamente por meio de vários suportes, ou na sequência de um manual didático, um roteiro acessível, de fácil checagem permitirá ao docente padronizar suas observações evitando atividades exploradas superficialmente ou apenas para cumprimento de carga horária. Outras abordagens teóricas como motivação, andragogia e English for Specific Purpose, embora não citados no roteiro, são partes constitutivas de alguns dos itens listados.

A sugestão do roteiro comungou com o fato de ser o PROEJA um programa que atende às especificidades do público da EJA conhecidamente desfalcada de materiais educacionais. No entanto, o roteiro não significa uma solução para o ensino-aprendizagem de LI haja vista a dimensão de alguns assuntos, principalmente aqueles que se referem à formação, escolha e crenças dos profissionais de ensino, além de outros meramente estruturais, mas que requerem atitudes políticas.

O levantamento dos dados evidenciou que, subjacente ao empobrecimento das atividades didáticas, estão fatores como a formação dos professores, a carga horária reduzida, material didático inadequado para a modalidade, a variedade dos cursos da área técnica, a jornada de trabalho extensa dos professores, a rotatividade dos mesmos, a pouca orientação sobre o programa, entre outros que interferem no processo de ensino-aprendizagem de LI nas turmas do PROEJA. 
Não podemos generalizar nossas conclusões como representativas do quadro educacional brasileiro, contudo não podemos negar a existência dos fatores levantados que interferem na qualidade da educação de jovens e adultos na rede pública. Entendemos assim que são necessárias mudanças pedagógicas, tecnológicas e estruturais.

Entre os vários fatores que influenciam negativamente no ensinoaprendizagem da língua inglesa no PROEJA, não foram mencionados, contudo cremos que subjazem crenças e conceitos ideológicos sobre a falta de aptidão para o idioma devido ao descrédito de sucesso direcionado às classes oprimidas.

\section{Notas}

' $O$ edital é lançado antes para que autores e editoras se adequem às normas exigidas antes da seleção e distribuição dos livros didáticos.

ii Este conceito de livro didático é detalhadamente discutido por Batista em O Conceito de "Livros Didàticos" In: BATISTA, A.A.G.;GALVÃO, A.M.de O. Livros escolares de leitura no Brasil: elementos para uma história. Campinas, SP: Mercado de Letras, 2009.p.4173

iii Os três fatores discutidos por Leffa em seu trabalho "Pra que estudar inglês, profe?: Auto exclusão em língua-estrangeira." são respectivamente:

1) a escola como reprodutora dos valores da classe dominante; 2) a universalização do ens ino nas décadas de 1960 e 1970; 3) falta de qualificação dos professores.

iv Passar os olhos por um texto para identificar os pontos principais, sem estudá-lo detalhadamente.

${ }^{\vee}$ Fazer uma leitura rápida do texto para buscar informações específicas.

\section{Referências Bibliográficas}

BARDIN, Laurence. Análise de conteúdo. Tradução de Luís Antero Reto e Augusto Pinheiro. Portugal, Lisboa: Edições 70, 1977.

BATISTA, A. A. G. Um objeto variável e instável: textos, impressos e livros didáticos. In: ABREU, Márcia (Org.). Leitura, história e história da leitura. Campinas, SP: Mercado de Letras, 1999. (Coleção Histórias de Leitura) 2a reimpressão Julho/2008.

BRASIL. Ministério da Educação, Secretaria da Educação Média e Tecnológica. Parâmetros Curriculares Nacionais: ensino médio: Linguagens, códigos e suas tecnologias/Ministério da Educação. Brasília: MEC/SEMTEC, 1999.

Secretaria de Educação Profissional e Tecnológica. Documento

Base do PROEJA, Programa Nacional de Integração da Educação Profissional com a Educação Básica na Modalidade de Educação de Jovens e Adultos. Educação Profissional Técnica de Nível Médio/Ensino Médio. Brasília: MEC, 2007. 


\section{SILID IV SIMAR \\ PUC-Rio - Dias 28, 29 e 30 de julho de 2015}

Secretaria de Educação Básica. Programa Nacional do Livro Didático, PNLD EJA 2011. Edital de Convocação/Ministério da Educação, Fundo Nacional de Desenvolvimento da Educação. Brasília: MEC, 2009.

FREIRE, Paulo. Pedagogia da autonomia: saberes necessários à pratica educativa. São Paulo: Paz e Terra, 2009 (Coleção Leitura).40a reimpressão

LEFFA, Vilson J. Pra que estudar inglês, profe?: Auto-exclusão em línguaestrangeira. Claritas, São Paulo, v. 13, n. 1, p. 47-65, maio 2007.

MARCUSCHI, L. A. Gêneros textuais: definição e funcionalidade. In: DIONíSIO, A.P.; MACHADO, A.R.; BEZERRA, M.A. (Orgs.). Gêneros textuais \& ensino. 4 ed., Rio de Janeiro: Lucerna, 2005. p. 19-36.

OLIVEIRA, Luciano Amaral. Ensino de língua estrangeira para jovens e adultos na escola pública. In: LIMA, D. C. de (Org.). Ensino e aprendizagem de língua inglesa: conversas com especialistas. São Paulo: Parábola Editorial, 2009. p. 21-30.

SOARES, Magda. Letramento. Um tema em três gêneros. $2^{a}$ ed. $11^{a}$ reimpressão. Belo Horizonte: Autêntica, 2006.

XAVIER, A.C.S. O hipertexto na sociedade da informação: a constituição do modo de enunciação digital. Tese de doutorado, Unicamp: inédito, 2002. 